\title{
Application of the lamp model equation to HID lamps with various voltage
}

\author{
Kazuyoshi MASUMI* and Hiroshi B⿸厂二
}

\begin{abstract}
The operating circuits for discharge lamps with various lamp voltages which differ from usual ones are analyzed by the simulation method. The coefficients of the mathematical model equation shown in the previous paper for different lamp voltages are determined by the assumption that the operating waveforms of the voltage and current of different voltage lamps are similar to those of commercially available lamps. In the case of various lamp voltages at rated power (400 W) operation, operating circuits of a reactor type and a reactor-capacitor type for the mercury discharge lamps are analyzed on a digital computer. For both of these types, operational characteristics at various ratios of lamp voltage to source voltage are obtained by this analysis. Optimization of operating circuits is discussed from various points of view, such as the circuit power factor, the lamp current fluctuation rate, the current wave peak factor, the capacitor voltage and the physical size.
\end{abstract}

\section{Introduction}

In the design of an operating circuit, there is the freedom to choose the ratio of lamp voltage to source voltage which is related to the performance of a lamp and the physical size and weight of the ballast. Since the theoretical analysis to choose the ratio has not been investigated clearly owing to the nonlinear and nonexplicit characteristics of the discharge lamp, it has been usually chosen through experimentation.

The relation between the lamp performance and the ratio of lamp voltage to source voltage is obtained by using the simulation method shown in a previous paper.

As coefficients of the mathematical model equation of the lamp used in this method are not constant for different voltage lamps, the coefficients are obtained by assuming that the voltage and current waveforms for each different voltage lamp are similar to those of commercially available lamps. The two operating circuits of a reactor-capacitor and a reactor type for the mercury discharge lamps are analyzed by this method for the various voltage lamps operated at the rated power. The optimum values of each circuit are discussed from the various points of view, such as the power factor, the lamp current fluctuation rate, the current waveform peak factor,

\footnotetext{
* Department of Electronics Engineering, Faculty of Engineering, Kobe University, Rokko Nada, Kabe, Japan.
}

the capacitor voltage and the physical size, and it is found that these analyzed conditions agree very well with the experimental ones.

\section{Model equation of HID lamps}

It is useful for an analysis of the circuital equation of the operating circuits for the discharge lamp to use the instantaneous conductance of a lamp. The model equation for the conductance of HID lamps was proposed in the previous papers ${ }^{23: 3}$. The model equation is

$$
\frac{d g_{u}}{d t}=A_{u} i_{u}^{2}-B_{u} g_{u^{2}}
$$

where $A_{u}$ and $B_{u}$ are constants, $g_{u}$ and $i_{u}$ are the instantaneous conductance and the instantaneous current of the usual voltage lamp (commercially available lamp), respetcively. In order to determine the constants $A_{v}$ and $B_{u}$ as accurately as possible, the measured values at $d v_{u} / d t=0$ and $d i_{u} / d t=0$ on the experimental waveforms for the usual voltage lamp are used ${ }^{3)}$, where $v_{u}$ is the instantaneous voltage of the usual voltage lamp.

Integration of Eq. (1) gives

$$
\int \frac{d g_{u}}{g_{u}{ }^{2}}=\int\left(A_{u} v_{u}^{2}-B_{u}\right) d t
$$

Since the value of the lamp conductance $g_{u}$ at $t=T / 2$ (half period) is equal to its value at $t=0$, the integral of the left hand side of Eq. (2) is zero. Then, Eq. (2) becomes 


$$
\int_{0}^{T / 2} v_{u}^{2} d t=\int_{0}^{T / 2} \frac{B_{u}}{A_{u}} d t=\frac{B_{u}}{A_{u}} \frac{T}{2} .
$$

This equation gives

$$
\sqrt{\frac{B_{u}}{A_{u}}}=\sqrt{\frac{2}{T} \int_{0}^{T / 2} v_{u}^{2} d t}=V_{u},
$$

where $V_{u}$ is the r.m.s. value of the usual lamp voltage. Thus, it is easily seen that the constants $A_{u}$ and $B_{\text {uv }}$ of Eq. (1) are related to the r.m.s. value of the usual lamp voltage.

The values of the constants $A_{a}$ and $B_{a}$ for lamps with different lamp voltages are determined by the following assumptions :

Assumption (a): The instantaneous voltage of different voltage lamps, $v_{a}$, is $K$ times as large as that of usual voltage lamps, $v_{u}$, at any given time, that is, $v_{a}=K v_{u}$.

Assumption (b): The instantaneous current of different voltage lamps, $i_{a}$, is $1 / K$ of that of usual voltage ones, $i_{n}$, at any given time, or $i_{a}=i_{u} / K$.

From the above assumptions, (a) and (b), the power of the different voltage lamps, $P_{a}$, is given as follows:

$$
P_{a}=\frac{2}{T} \int_{0}^{T / 2} v_{a} i_{a} d t=\frac{2}{T} \int_{0}^{T / 2} v_{u} i_{u} d t
$$

Hence, the above assumptions are useful under the condition that the lamp powers of various voltage lamps equal each other. Also, the r.m.s. value of the different lamp voltages, $V_{a}$, is derived from assumption (a) as follows:

$$
V_{a}=\sqrt{\frac{2}{T} \int_{0}^{T / 2} v_{a}^{2} d t}=\sqrt{\frac{2}{T} \int_{0}^{T / 2}\left(K v_{u}\right)^{2} d t}=K V_{u} .
$$

The factor $K$ in both assumption becomes

$$
K=\frac{V_{a}}{V_{u}} .
$$

On the other hand, the instantaneous conductance of the different voltage lamps $g_{a}$ becomes

$$
g_{a}=\frac{i_{a}}{v_{a}}=\frac{g_{u}}{K^{2}} .
$$

From Eqs. (1) and (6), the mathematical model equation becomes

$$
\begin{aligned}
\frac{d g_{a}}{d t} & =\frac{1}{K^{2}} \frac{d g_{u}}{d t}=A_{u} i_{a}^{2}-K^{2} B_{u} g_{a}^{2} \\
& =A_{a} i_{a}{ }^{2}-B_{a} g_{a}{ }^{2} . \ldots \ldots \ldots \ldots \ldots \ldots \ldots
\end{aligned}
$$

Then, constants $A_{a}$ and $B_{a}$ for different voltage voltage lamps are given by Eqs. (5 ) and (7) as follows:

$$
A_{a}=A_{u}
$$

and $\quad B_{a}=K^{2} B_{u}=A_{u} V_{a}^{2}$.

From Eqs. (7) and (8), finally, the generalized model equation for the various voltage lamps is given in a more convenient form as follows:

$$
\frac{d g}{d t}=A_{u}\left(i^{2}-V^{2} g^{2}\right)
$$

where $g$ and $i$ are instantaneous conductance and instantaneous current, respectively, and $V$ is the r.m.s. value for the lamp voltage at the rated power operation.

\section{Analysis}

Two types of operating circuits for a $400 \mathrm{~W}$ mercury lamp are analyzed by using the values of $A_{\psi}=3.33\left(V^{-1} A^{-1} \sec ^{-1}\right)^{3)}$ and $f=60 \mathrm{~Hz}$.

\subsection{A reactor-capacitor type operating circuit}

Circuital equations for an operating circuit of the reactor-capacitor type shown in Fig. 1 are as follows :

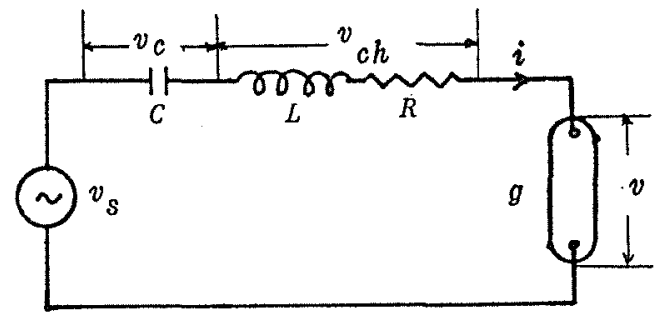

Fig. 1 Reactor-capacitor type operating circuit for a mercury discharge lamp.

$$
\frac{d i}{d t}=\left\{\sqrt{2} V_{s} \sin 2 \pi f t-\left(R+\frac{1}{g}\right) i-v_{c}\right\} / L
$$

and $\frac{d v_{c}}{d t}=\frac{i}{C}$,

where $V_{\varepsilon}$ is the r.m.s. value of the source voltage, $f$ is the frequency of the source voltage, $L$ is the inductance of the reactor, $R$ is the resistance of the reactor, $C$ is the capacitance of the capacitor, and $v_{c}$ is the instantaneous voltage of the capacitor. Using Eqs. (9) and (10), this operating circuit can be analyzed.

The relation between inductance $L$ and the ratio

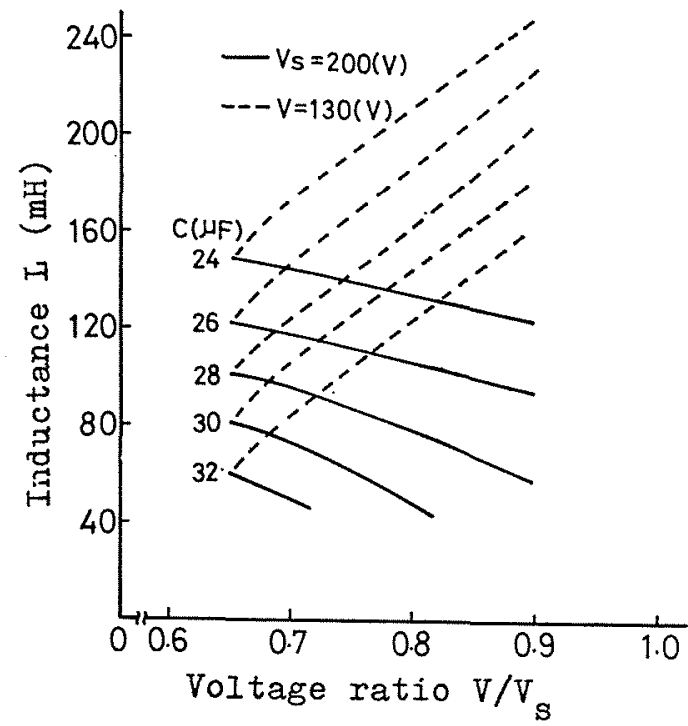

Fig. 2 Relation between the inductance $L$ and the ratio $V / V_{s}$ for various values of capacitance $C$. 
of the lamp voltage to source voltage $V / V$ is calculated with respect to the various values of capacitance $C$ as shown in Fig. 2. In Fig. 2, the broken. and solid lines are obtained values for the usual voltage lamp $(V=130 \mathrm{~V}$, commercially available lamp) operated at various source voltages and for lamps with different lamp voltages operated at constant source voltage $\left(V_{s}=200 \mathrm{~V}\right)$, respectively. It is shown that the inductance $L$ reduces as the capacitance $C$ increases. In the case of the usual lamp voltage, the inductance $L$ increases as the ratio $V / V$ increases. However, in the case of the usual source voltage, the inductance $L$ decreases as the ratio $V / V$ increases.

Next, the relation between the r.m.s. value of the lamp current $I$ and the ratio $V / V s$ is shown in Fig. 3. If a large capacitance is used in order to reduce the inductance, the lamp current increases. In the case of the usual source voltage, if a ratio $V / V_{s}$, larger than the usual one $(0.65)$, is used, the lamp current can be decreased, and thus the wire size of a source line can be made smaller than

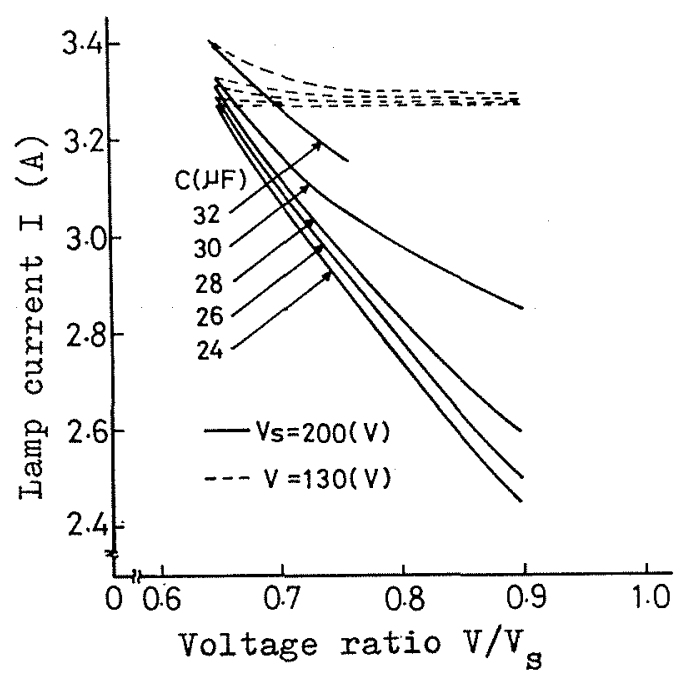

Fig. 3 Relation between the lamp current $I$ and the ratio $V / V_{s}$ for various values of capacitance $C$.

the usual one.

The relations between $V_{c}$ or $V_{c h}$ and the ratio $V / V_{s}$ are shown in Fig. 4, where $V_{c}$ and $V_{c h}$ are the r.m.s. values of the voltage across the capacitor and reactor. Moreover, the relations between the values of $V A_{c}$ or $V A_{c h}$ and the ratio $V / V$ s are shown in Fig. 5, where $V A_{c}$ and $V A_{\text {ch }}$ are the apparent powers of the capacitor and reactor, respectively. As shown in Figs. 4 and 5, these values decrease as the capacitance $C$ increases. In the case of the usual lamp voltage, the values of $V_{c h}$ and $V A_{c h}$ increase as the ratio $V / V_{\text {s }}$ increases, and the values of $V_{c}$ and $V A_{c}$ are nearly constant. On the other hand, in the case of the usual source voltage, these voltages and apparent powers decrease as the ratio $V / V_{s}$ increases.

In this operating circuit, $V_{c}$ is greater than $V_{c h}$, as is shown in Fig. 4, and the ballast voltage $V_{b}$

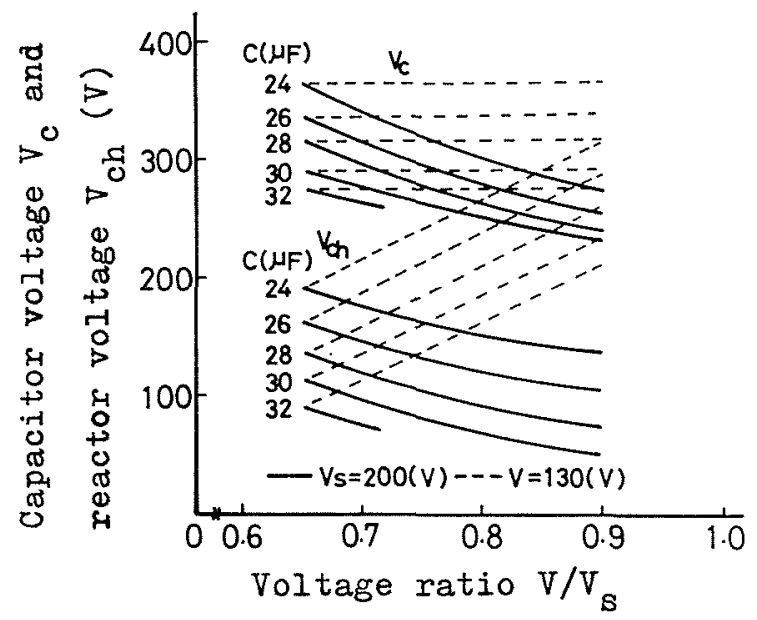

Fig. 4 Relations between the capacitor voltage $V_{c}$ or the reactor voltage $V_{c h}$ and the ratio $V / V_{s}$ for the various values of capacitance $\mathrm{C}$.

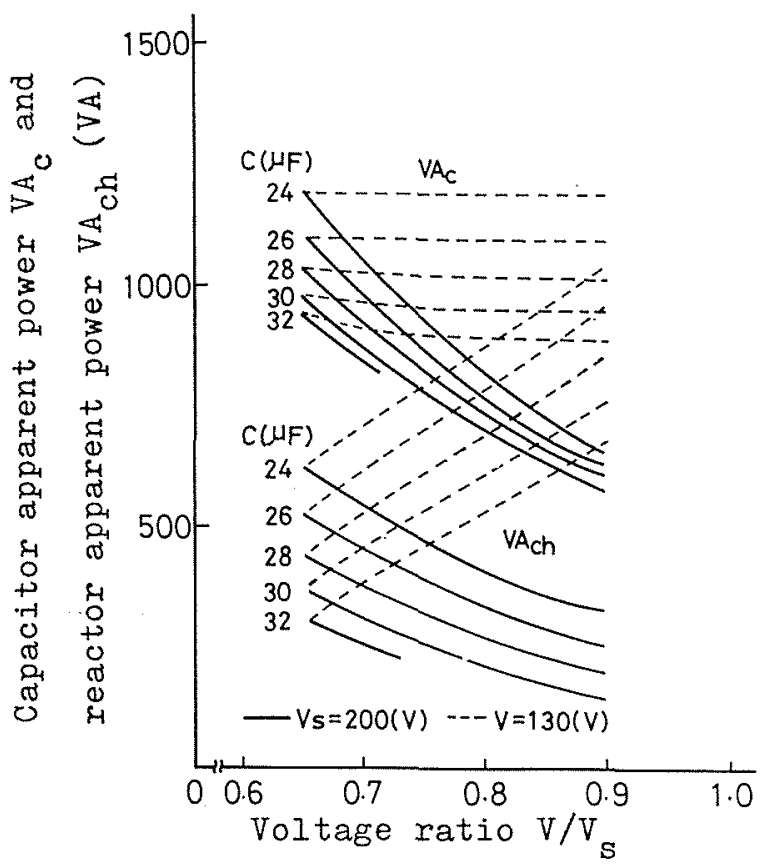

Fig. 5 Relations between the apparent powers of the reactor and the capacitor and the ratio $V / V_{s}$ for various values of capacitance $C$.

is nearly equal to $\left(V_{c}-V_{c h}\right)$. Now, let us consider the case of a large value of ratio $V / V_{s}$ for the usual lamp. If the capacitance $C$ is fixed, $V_{c}$ is invariable because of the constant lamp current at the rated power. Thus, it is obvious from broken lines in Fig. 4 that $V_{c h}$ is greater than usual one. Hence, it is found that the inductance $L$ must be greater than the usual one as shown by broken lines in Fig. 2.

The relation between the current fluctuation rate $I_{\varepsilon}$ and the ratio $V / V s$ is shown in Fig. 6. By $I_{c}$ is meant $\frac{\Delta I}{I} / \frac{\Delta V_{s}}{V_{s}}$. The current fluctuation rate $I_{\text {s }}$ 


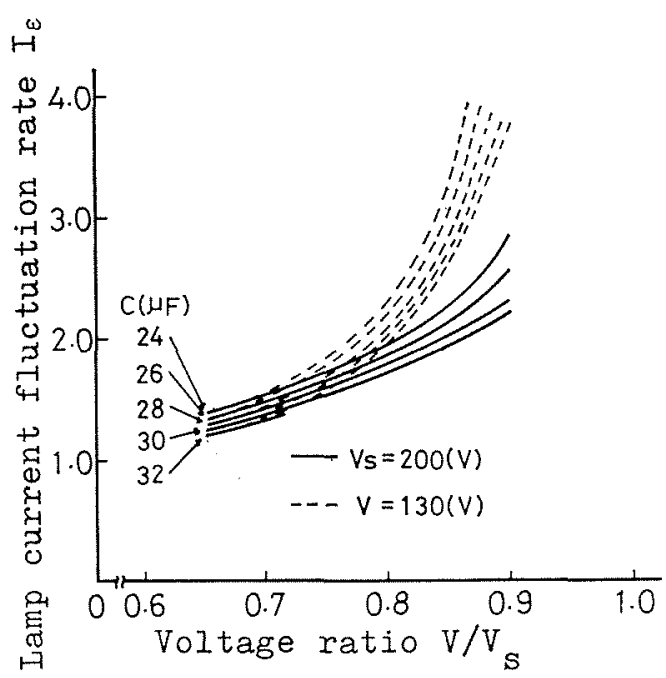

Fig. 6 Relation between the lamp current fuctuation rate $I_{s}$ and the ratio $V / V_{*}$ for various values of capacitance $C$.

in the case of the usual lamp voltage increases more rapidly against the ratio $V / V$, in comparison to that in the case of the usual source voltage.

\subsection{A reactor type operating circuit}

As the circuital element is only a reactor in the operating circuit of reactor type, a circuital equation for this circuit is as follows:

$$
\frac{d i}{d t}=\left\{\sqrt{2} V_{s} \sin 2 \pi f t-\left(R+\frac{1}{g}\right) i\right\} / L \ldots \text { (11) }
$$

Analysis is much simpler than in the case of previous operating circuit. The relation between the inductance $L$ and the ratio $V / V$, is shown in Fig. 7. The inductance $L$ values are $56 \mathrm{mH}$ in the lamp voltage of $130 \mathrm{~V}$ and $90 \mathrm{mH}$ in the source voltage of $200 \mathrm{~V}$ when the ratio $V / V$, is 0.8 . In order to reduce the inductance $L$, it is advantageous to choose a source voltage as near as possible to the lamp voltage. However, the ratio $V / V_{s}$ must

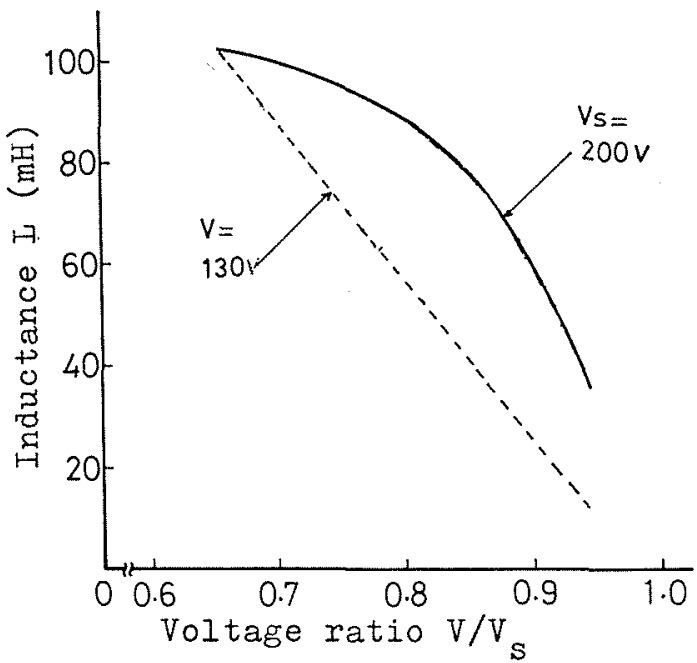

Fig. 7 Relation between the inductance $L$ and the ratio $V / V_{s}$ (reactor type).

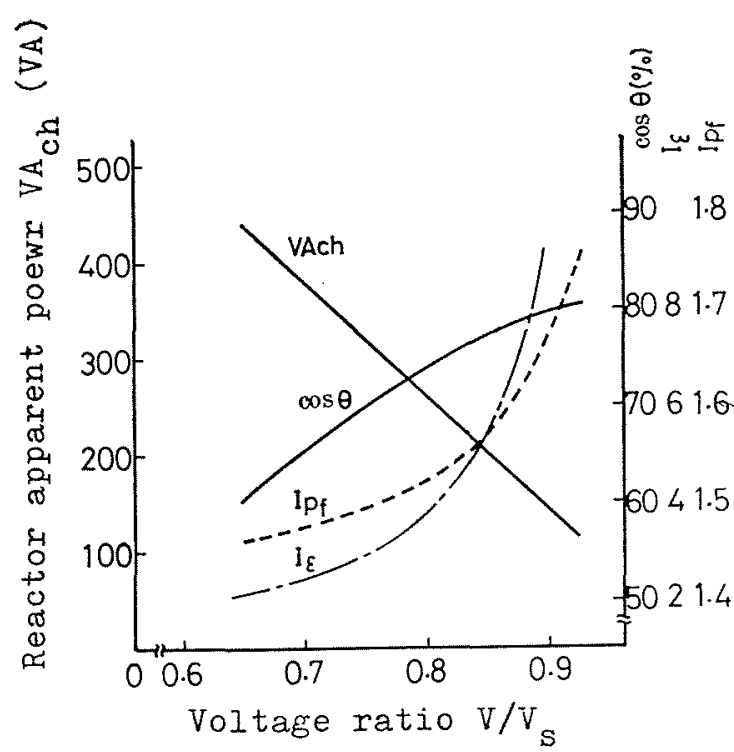

Fig. 8 Relations bctween various characteristics and the ratio $V / V_{s}$ (reactor type).

be chosen below 0.85 to avoid unstable operation of the mercury lamp.

Also, the values of $V A_{c h}, \cos \theta, I_{p f}$ and $I_{c}$ are plotted in Fig. 8 against the ratio $V / V_{s}$ which is obtained by changing $V$ or $V_{s}$, where $I_{p t}$ is the waveform peak fatcor of the lamp current, and $\cos \theta$ is the power fatcor of the operating circuit. For example, when 0.8 is taken as the ratio $V / V_{s}$, the lamp current fluctuation rate $I_{c}$ will be about 4 . Therefore, if a variation of the lamp current below $\pm 20 \%$ is desired, the variation of the source voltage below $\pm 5 \%$ is required. In this case, the apparent power of the reactor is about one half as large as the usual one, and the power factor may be increased to $75 \%$.

\section{Prediction of optimum condition}

The eletrical characteristics of the operating system for the various lamp and source voltages of the reactor-capacitor type are discussed in the previous chapter. However, the desirable values for the lamp and source voltages can not be determined by these electrical characteristics immediately. But, by evaluating and discussing these values systematically, the optimum values may be predicted from the point of view of reducing the physical size, weight and cost of the capacitor and the reactor. The cost of a capacitor is related to its working voltage. Hence, in order to reduce the physical size, weight and cost, it is desirable to decrease these apparent powers and the working voltage.

For example, the above values for optimum design can be taken as follows: (1) $V A_{c}$ is minimum, (2) $V_{0} \leqq 260 \mathrm{~V}$, (3) $I_{s} \leqq 2$, (4) $I_{p f} \leqq 1.7$ and (5) $\cos \theta \geqq 0.7$. The relation between inductance and capacitance is shown in Figs. 9(a) and (b) in the cases of the various lamp and source voltages. The hatched regions in Fig. 10 satisfy the above 


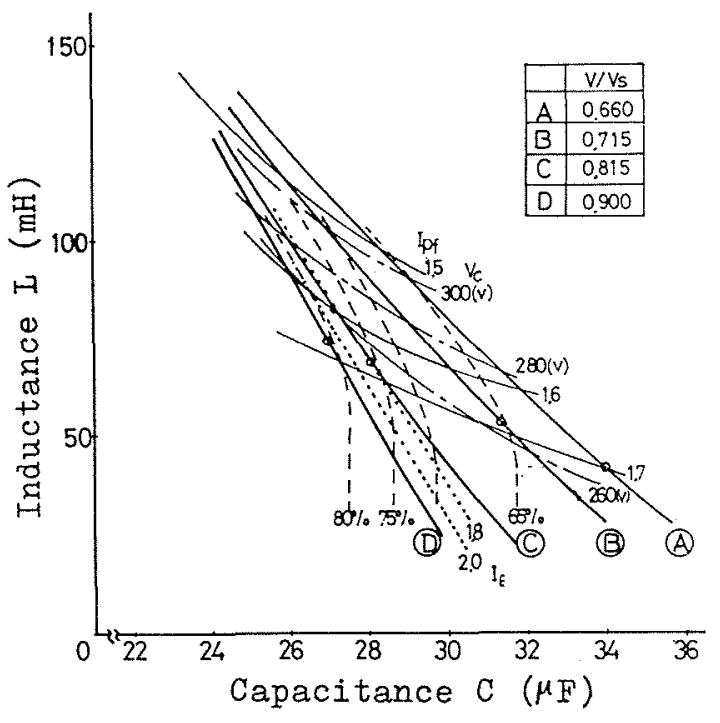

(a)

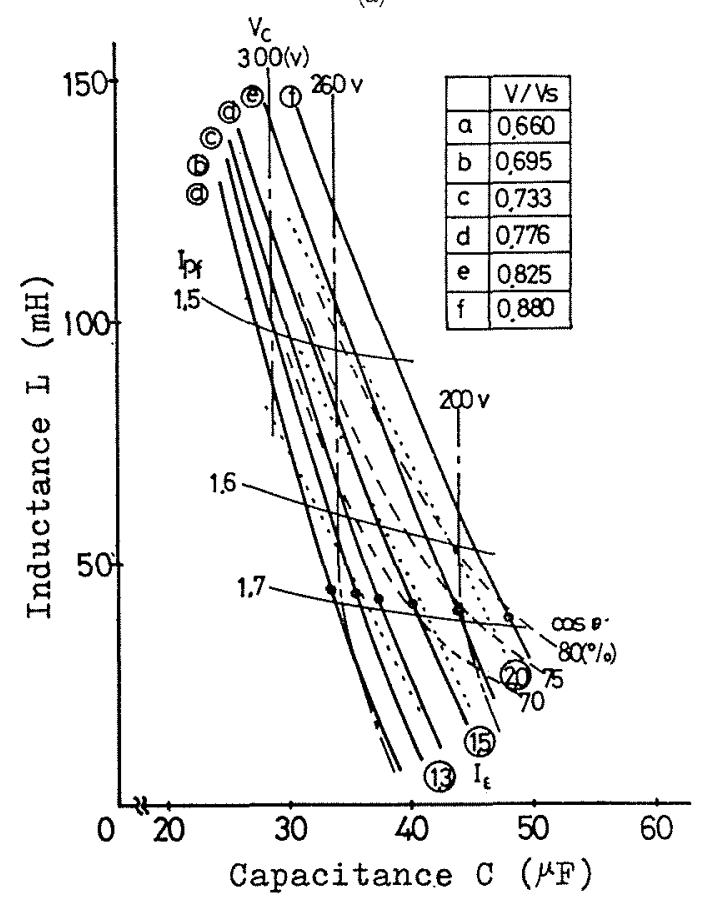

(b)

Fig. 9 (a) Relations between the inductance $L$ and the capacitance $C$ for various ratios $V / V_{s}$ at the source voltage $V_{s}=200 \mathrm{~V}$; (b) Relation between the inductance $L$ and the capacitance $C$ for various ratios $V / V_{s}$ at the lamp voltage $V=130 \mathrm{~V}$.

conditions, $(2) \sim(5)$. In these regions, the optimum points which satisfy condition (1) above are shown by the marks $O$. From above results, the ratio $V / V_{s}$ can be seen to be 0.815 at the source voltage $200 \mathrm{~V}$. Therefore, the results $V=163 \mathrm{~V}, C=28 \mu \mathrm{F}$ and $L=70 \mathrm{mH}$ are obtained. When, the ratio $V / V$ s is 0.813 at the lamp voltage $130 \mathrm{~V}$, the results $V_{s}=160 \mathrm{~V}, C=44 \mu \mathrm{F}$ and $L=44 \mathrm{mH}$ are obtained.

Moreover, assuming that the value 2 is taken as the lamp current fluctuation rate $I_{s}$, the ratio $V / V$ s is approximately 0.9 as shown Fig. 9(a). In this case, the lamp voltage is $180 \mathrm{~V}$ when the source

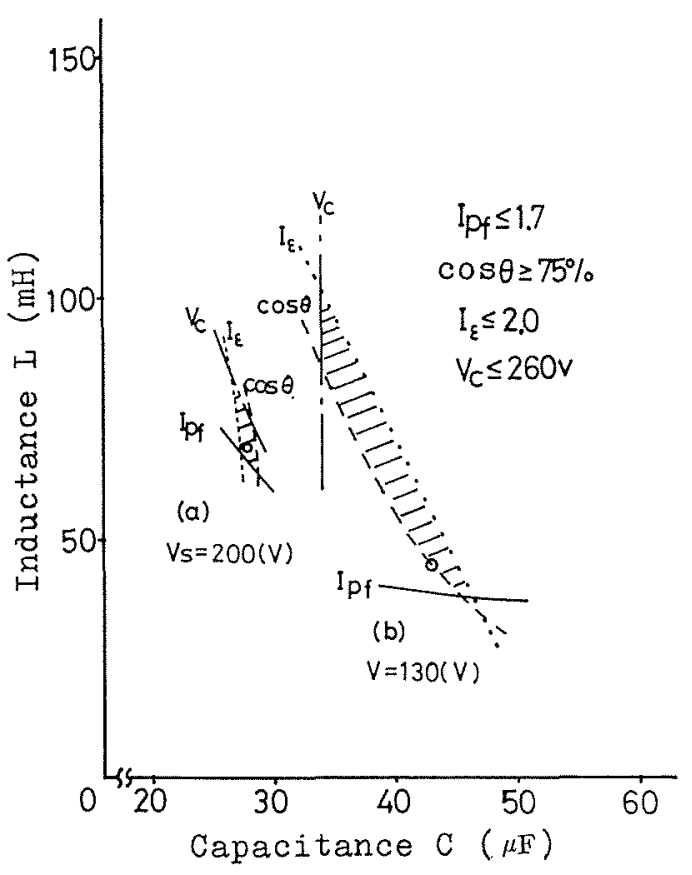

Fig. 10 Optimum regions of the values of the inductance and the capacitance.

voltage is $200 \mathrm{~V}$, and the circuital power factor becomes $80 \%$.

\section{Comparison of calculation and measurement}

The comparison of the calculated and measured values for the electrical characteristics of operating circuits under the various conditions is shown in Table 1. Consequently, it is clear that the calculated error is within a small percentage.

Also, the operating waveforms for the ratio $V / V_{s}=0.9$ in the reactor-capacitor type and 0.82 in the reactor type are shown in Figs. $\mathbf{1 1}$ (a) and (b). The left and right parts of Figs. 11(a) and (b) are the calculated and measured waveforms, respectively. Hence, it is evident that the detailed waveforms which are obtained by the calculation agree very well with the measured ones.

\section{Conclusions}

This paper shows how the coefficients of the mathematical model equation for HID lamps proposed by authors can be described in the case of the various voltage lamps. The coefficients can be determined by assuming that the waveforms of voltage and current of these lamps are similar to those of the commercially available ones. Considering the relation between the coefficients and the r.m.s. values of these lamps, the generalized mathematical model equation is derived as follows:

$$
\frac{d g}{d t}=A_{u}\left(i^{2}-V^{2} g^{2}\right)
$$

The operating circuits of both the reactor-capaci- 
Table 1 Comparison of measured and calculated values.

\begin{tabular}{|c|c|c|c|c|c|c|c|c|c|c|c|c|c|c|}
\hline type & $\left|\begin{array}{c}\text { source } \\
\text { voltage } \\
\text { (V) }\end{array}\right|$ & $\begin{array}{c}\text { voltage } \\
\text { ratio }\end{array}$ & $\begin{array}{c}\text { induance } \\
\text { (mH) }\end{array}$ & $\begin{array}{c}\text { capacitance } \\
(\mu \mathrm{F})\end{array}$ & $\begin{array}{c}\operatorname{lamp} \\
\text { roltage } \\
\text { (V) }\end{array}$ & $\begin{array}{c}\operatorname{lamp} \\
\text { current } \\
\text { (A) }\end{array}$ & $\begin{array}{l}\text { current } \\
\text { peak } \\
\text { factor }\end{array}$ & $\begin{array}{c}\text { current } \\
\text { fluctuation }\end{array}$ & $\begin{array}{c}\text { reactor } \\
\text { voltage } \\
\text { (V) }\end{array}$ & $\begin{array}{c}\text { capacitor } \\
\text { voltage } \\
\text { (V) }\end{array}$ & $\begin{array}{l}\text { reactor } \\
\text { apparent } \\
\text { power } \\
\text { (VA) }\end{array}$ & $\begin{array}{l}\text { capacitor } \\
\text { apparent } \\
\text { power } \\
\text { (VA) }\end{array}$ & $\begin{array}{l}\text { pourer } \\
\text { factor } \\
\text { (\%) }\end{array}$ & \\
\hline \multirow{6}{*}{$\mathrm{L}-\mathrm{C}$} & \multirow[t]{2}{*}{200} & \multirow[t]{2}{*}{0.66} & \multirow[t]{2}{*}{43} & \multirow[t]{2}{*}{34} & 132 & 3.5 & 1.73 & 1.3 & 75 & 263 & 263 & 926 & 60 & calculated \\
\hline & & & & & 132 & 3.5 & 1.73 & 1.3 & 76 & 264 & 268 & 932 & 59 & measured \\
\hline & \multirow[t]{2}{*}{200} & \multirow[t]{2}{*}{0.82} & \multirow[t]{2}{*}{71} & \multirow[t]{2}{*}{28} & 163 & 2.8 & 1.65 & 1.8 & 92 & 257 & 258 & 717 & 75 & calculated \\
\hline & & & & & 163 & 2.8 & 1.69 & 1.6 & 91 & 250 & 256 & 707 & 76 & measured \\
\hline & \multirow[t]{2}{*}{160} & \multirow[t]{2}{*}{0.83} & \multirow[t]{2}{*}{44} & \multirow[t]{2}{*}{44} & 132 & 3.5 & 1.67 & 1.7 & 71 & 202 & 247 & 702 & 76 & calculated \\
\hline & & & & & 132 & 3.5 & 1.65 & 1.5 & 73 & 203 & 251 & 713 & 75 & measured \\
\hline \multirow{6}{*}{$\mathrm{L}$} & \multirow[t]{2}{*}{200} & \multirow[t]{2}{*}{0.66} & \multirow[t]{2}{*}{93} & \multirow[t]{2}{*}{-} & 132 & 3.3 & 1.47 & 2.2 & 122 & \multirow[t]{2}{*}{-} & 403 & \multirow[t]{2}{*}{-} & 67 & calculated \\
\hline & & & & & 132 & 3.3 & 1.49 & 2.4 & 123 & & 403 & & 64 & measured \\
\hline & \multirow[t]{2}{*}{200} & \multirow[t]{2}{*}{0.82} & \multirow[t]{2}{*}{74} & \multirow[t]{2}{*}{-} & 163 & 2.7 & 1.54 & 4.1 & 86 & \multirow[t]{2}{*}{-} & 234 & \multirow[t]{2}{*}{-} & 77 & calculated \\
\hline & & & & & 163 & 2.8 & 1.53 & 3.5 & 83 & & 229 & & 77 & measured \\
\hline & \multirow[t]{2}{*}{160} & \multirow[t]{2}{*}{0.83} & \multirow[t]{2}{*}{44} & \multirow[t]{2}{*}{-} & 132 & 3.4 & 1.56 & 4.7 & 64 & \multirow[t]{2}{*}{-} & 215 & \multirow[t]{2}{*}{-} & 79 & calculated \\
\hline & & & & & 132 & 3.4 & 1.57 & 4.2 & 62 & & 210 & & 77 & measured \\
\hline
\end{tabular}

Calculated waveforms
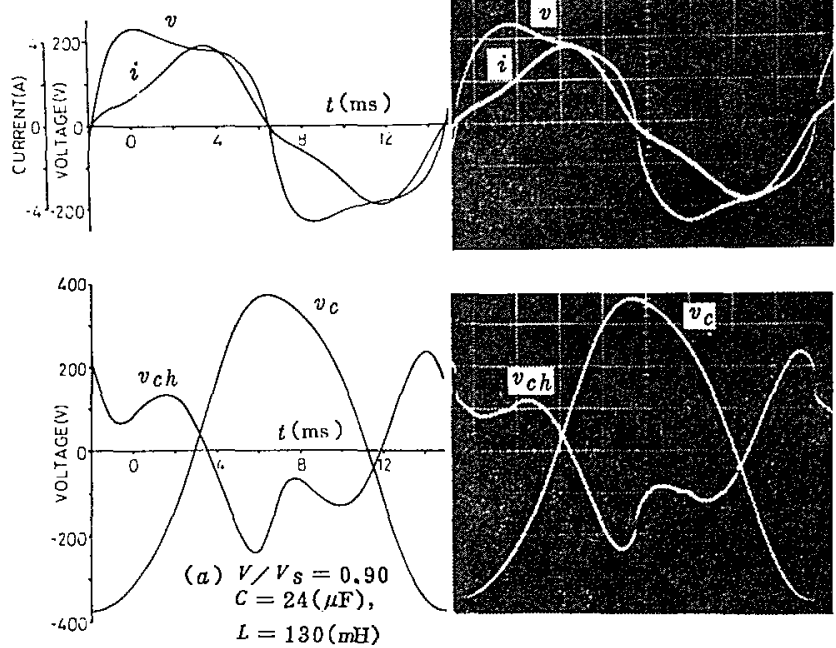

Measured waveforms

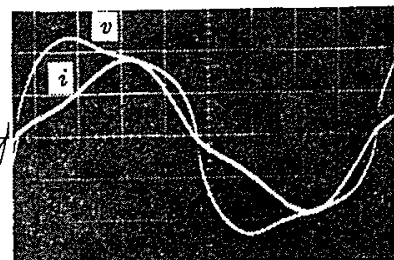

Calculated waveforms
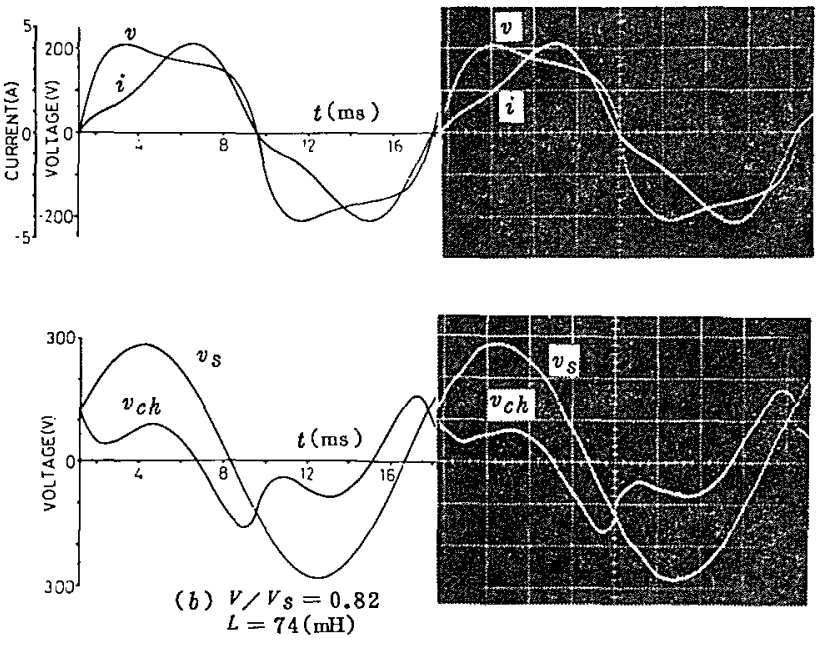

Fig. 11 (a) Operating waveforms for ther atio $V / V_{s}=0.9$ in the reactor-capacitor type;

(b) operating waveforms for the ratio $V / V_{s}=0.82$ in the reactor type.

tor and reactoy types for the $400 \mathrm{~W}$ mercury discharge lamps with various rated lamp voltages are analyzed by the simulation method using the above equation. Then, the detailed relations between the circuital constants or the electrical characteristics and the ratio of lamp voltage to source voltage are obtained. Optimum conditions for both operating circuits are discussed, and these results for the optimum conditions mentioned above agree very well with experiments.

It is found from these results that this method of analysis is very useful to analyze the circuits for the various rated lamp voltages and to predict the optimum condition for them.

\section{References}

(1) H. Bō and K. Masumi: "Analysis of Operating Circuits for Discharge Lamps by Simulation Method", J. Illum. Engng Soc., 5, 2, Jannuary, (1976) p. 92.

(2) K. Masumi and H. Bō: "On the Mathematical Models for Equivalent Conductance of Discharge Lamps", J. Illum. Engng. Inst. Japan, 57, 6, June, (1973) p. 342, (in Japanese).

(3) H. Bō, K. Masumi and M. Kaneda: "On the Differential Equations for the High Pressure Discharge Lamps", Memories of the Faculty of Engineering, Kobe University, No. 18, (1972) p. 195.

(1976. 12. 8, 1977. 3. 7) 